\title{
SMART AUTOMATION IN RAILWAY SYSTEM
}

\author{
Arundas M H $\mathbf{H}^{1}$, Nikhil Babu T $\mathbf{S}^{\mathbf{2}}$, Lijo K J $\mathbf{J}^{3}$ \\ ${ }^{I}$ Baselios Thomas I Catholicose College of Engineering and Technology, Koothatukulam, India \\ ${ }^{2}$ Baselios Thomas I Catholicose College of Engineering and Technology, Koothatukulam, India \\ ${ }^{3}$ Baselios Thomas I Catholicose College of Engineering and Technology, Koothatukulam, India
}

\begin{abstract}
Now a day we are using over bridges for crossing the rail and manual controlling mechanism for the railway gates. But most of the passengers are not utilizing this facility and they will cross the rail directly and leads to accidents. Also the careles sness of the gate keeper or absence may lead to accidents at the railway crossings. In this project we are introducing a new intelligent platform which reduces accidents and make an easy passage for passengers from one platform to other platform and also an automatic railway gate which is controlled by a computer.
\end{abstract}

The proposed system consists a detection system, microcontroller unit and motor driver system. The main advantages project is, it reduces the accidents at the railway crossing and platforms and provide an easy passage for the passengers.

Keywords- microcontroller, stepper motor, railway system, dc motor

\section{INTRODUCTION}

Railway system is the most dependent transportation medium in our country. Thousands of people daily depends on railway transportation. And also a large number of human beings losses their lives due to carelessness and unawareness about railway system. Most of the people do not uses the over bridges and directly crosses the railway track. This leads to the major number of accidents. Also the level crosses without watchmen will also leads to accidents. In order to reduce the number of these kind of accidents here proposing automated railway system for better protection. The objective of the Intelligent Rail Crossing platform system is to control the platform from the microcontroller which alerts the passengers about the arrival of the train and controls the platform automatically. The objective of gate control system is to close the railway gate when the train approaches the gate and to prohibit the vehicles to pass by and to open the railway gate as the train leaves completely from the railway gate area automatically. The two components of the system are

A. Railway Platform control

B. Railway gate control

\section{RAILWAY PLATFORM CONTROL}

The project comprises three major parts namely,

- Detection system

- Controlling system

- Alerting system

\subsection{Detection System}

The main components of the project are two IR sensors which are placed at both sides of the station. One of the IR sensor that detect the arrival of train and the other IR sensor placed at the end side of the station detects the departure of the train.

\subsection{Controlling System}

When the train crosses the first IR sensor, which is kept near the rail with a predefined distance from the platform, the microcontroller will send a signal to the motor and hence the platform is get removed or opened. When the train crosses the second IR sensor, microcontroller will send a signal to the motor and hence the platform is get closed.

\subsection{Alerting System}

In our project for the alerting purposes we mainly use two components, one is the signal led and the other is buzzer. Three LEDs, Red, yellow and Green have been used in our project is to inform the passengers about the status of the train as well as platform. Yellow LED glows, when the train cuts the first IR sensor and the passenger can clear the platform. The Red LED glows when the train is about to cross the platform. And the Green LED glows, when the train has crossed the second IR sensor at end side of the station and the passengers are allowed to use the platform. The buzzer is used in our project to signal the crossers-by about the status of the train. The buzzer will activate, when the train is approaching the station. 


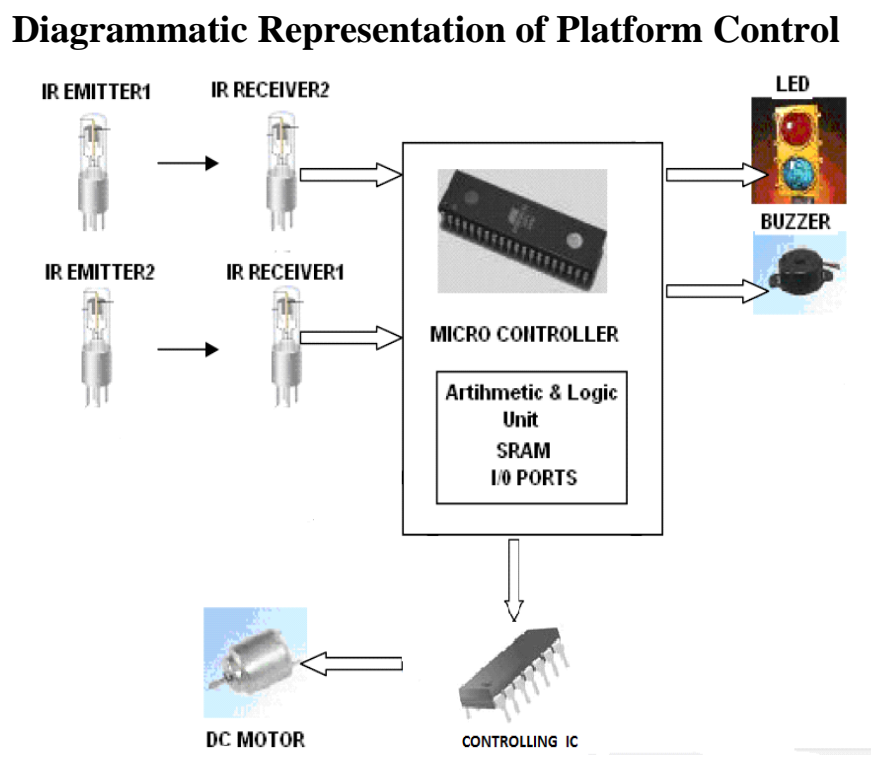

Fig 1: block diagram of platform control

\section{WORKING PRINCIPLE OF PLATFORM CONTROL}

The IR receiver is a NPN transistor and the base current is produced by the infrared (IR) rays coming from IR transmitter. The comparator negative terminal connected to the collector of IR receiver. The comparator positive terminal connected across the potentiometer and the potentiometer is used to adjust the reference voltage. The reference voltage is above the IR receiver's collector output in conducting time. The Comparator chip LM393 compares the collector output of the IR Receiver with a prefixed voltage signal. The comparator negative terminal voltage is higher than prefixed voltage of positive terminal and comparator provide low signal to the microcontroller. The comparator negative terminal voltage is lower than prefixed voltage of positive terminal and comparator provide high signal to the microcontroller.

The microcontroller processes the input signal from the IR sensors and produce corresponding output with respect to input signal. The LEDs are connected in negative logic and LEDs become active, when providing a low signal. The microcontroller provide low signal to the LED and the LED will glow. The microcontroller provide high signal to the LED and the LED will off. The buzzer is connected to the collector of a NPN transistor BC107 and the base of NPN transistor $\mathrm{BC} 107$ connected to the microcontroller. When microcontroller provide high signal to the base of the transistor BC 107, the transistor become active and the buzzer will activated. When microcontroller provide low signal to the base of the transistor and the transistor become inactive also buzzer will inactive

The microcontroller provides two input signal to the driver IC L293D. The motor can be stop by providing same input (high or low) to both input terminals. The motor is directly coupled with platform by using a linear drive mechanism. The linear drive mechanism is converting the mechanical rotation of the motor to linear motion. Then the dc motors rotates in anti-clockwise direction and remove the platform from the track. The dc motor rotates clockwise direction and the platform again comes back to the normal position. When the train cuts the first IR sensor, the first IR receiver acts as open switch and there will be no drop in collector voltage. Now the output at the collector end is $\operatorname{Vcc}(5 \mathrm{~V})$ voltage. This output is given to the negative terminal of the comparator chip LM393, which compares it witha prefixed voltage level at the positive terminal. Now negative terminal voltage is higher than positive terminal voltage and the comparator provide high signal to the microcontroller. The microcontroller will activate the buzzer and yellow LED for few seconds. After the few seconds, the microcontroller will activate the buzzer and red LED. At the same time microcontroller also provide corresponding signal to the motor driver IC and the driver IC provide signal to the motor. Then the dc motors rotates in anti-clockwise direction and remove the platform from the track.

When the train cuts the second IR sensor, the second IR receiver acts as open switch and there will be no drop in collector voltage. Now the output at the collector end is given to the negative terminal of the comparator chip LM393, which compares it with a prefixed voltage level at the positive terminal. Now negative terminal voltage is higher than positive terminal voltage and the comparator provide high signal to the microcontroller. The microcontroller will activate the buzzer and red LED. At the same time microcontroller also provide corresponding signal to the motor driver IC and the driver IC provide signal to the motor. The dc motor rotates clockwise direction and the platform again comes back to the normal position.

When there is no detection of the train, the IR receivers act as closed switch and there some drop in collector voltage. Now the output at the collector end is (Vcc-drop) voltage. This output is given to the negative terminal of the comparator chip LM393, which compares it with a prefixed voltage level at the positive terminal. Now negative terminal voltage is lower than positive terminal voltage and the comparator provide high signal to the microcontroller. The microcontroller will activate the green LED only. At that time microcontroller will not provide any input signal to the motor driver IC. When the two input of the motor driver IC become equal and motor driver IC will not provide any output to the motor. Then the motor will remains in standby condition. 


\subsection{Characteristic curves of DC machine}

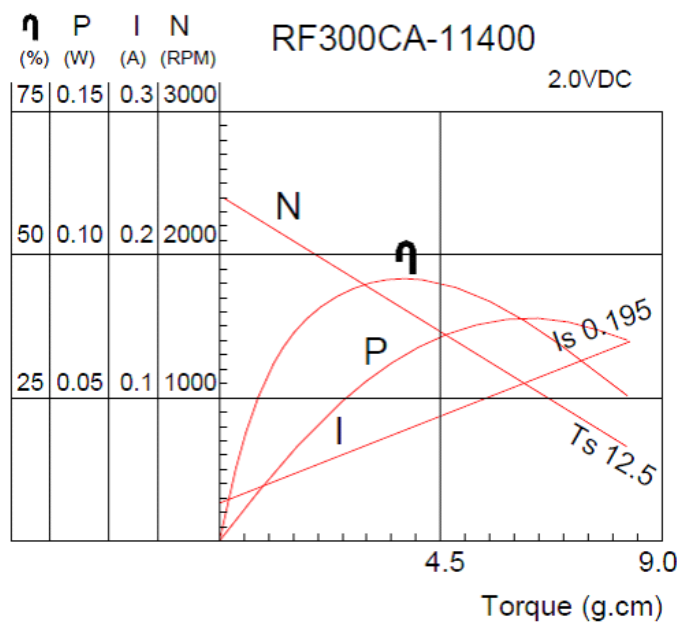

Fig 2 dc machine characteristics

\section{RAILWAY GATE CONTROL}

The railway gate control mechanism consists of three major components as follows

- Detection System

- Controlling System

- $\quad$ Alert System

The railway gate controlling is based on the same principle used in the controlling of railway platform. Here two sets of infrared sensors are used to detect the presence of the train near the railway gate. As the train reaches the railway gate, the first set of IR receiver-transmitter section. This output signal from the IR sensor is fed to the comparator IC (LM393). The comparator negative terminal voltage is higher than prefixed voltage of positive terminal and comparator provide low signal to the microcontroller. The comparator negative terminal voltage is lower than prefixed voltage of positive terminal and comparator provide high signal to the microcontroller.

The microcontroller receives the signal from the comparator and produce corresponding output at predefined ports.

The railway gate is actually connected to stepper motors which can carry heavier loads and can provide a stepped output to move the railway gate. In order to control the stepper motor by the microcontroller, we are using a driver IC L293D. The microcontroller provides two inputs to the driver IC L293D. The motor is directly coupled with the gate by a gear system. The gear system is used to increase the torque of the output of stepper motor. The stepper motor rotates $90^{\circ}$ direction to open or close the gate.

When the train cuts the first IR sensor, the first IR receiver acts as open switch and there will be no drop in collector voltage. Now the output at the collector end is $\operatorname{Vcc}(5 \mathrm{~V})$ voltage. This output is given to the negative terminal of the comparator chip LM393, which compares it with a prefixed voltage level at the positive terminal. Now negative terminal voltage is higher than positive terminal voltage and the comparator provide high signal to the microcontroller. The microcontroller will activate the buzzer. At the same time microcontroller also provide corresponding signal to the motor driver IC and the driver IC provide signal to the motor. Then the stepper motor rotates in clockwise direction and close the gate automatically.

When the train cuts the second IR sensor, the second IR receiver acts as open switch and there will be no drop in collector voltage. Now the output at the collector end is Vcc $(5 \mathrm{~V})$ voltage. This output is given to the negative terminal of the comparator chip LM393, which compares it with a prefixed voltage level at the positive terminal. Now negative terminal voltage is higher than positive terminal voltage and the comparator provide high signal to the microcontroller. The microcontroller will activate the buzzer. At the same time microcontroller also provide corresponding signal to the motor driver IC and the driver IC provide signal to the motor. The stepper motor rotates in anti-clockwise direction and the gate again comes back to the normal position.

When there is no detection of the train, the IR receivers act as closed switch and there some drop in collector voltage. Now the output at the collector end is (Vcc-drop) voltage. This output is given to the negative terminal of the comparator chip LM393, which compares it with a prefixed voltage level at the positive terminal. Now negative terminal voltage is lower than positive terminal voltage and the comparator provide high signal to the microcontroller. The microcontroller will activate the green LED. At that time microcontroller will not provide any input signal to the motor driver IC. When the two input of the motor driver IC become equal and motor driver IC will not provide any output to the motor. Then the motor will remains in standby condition.

\section{Diagrammatic Representation of the Gate Control}

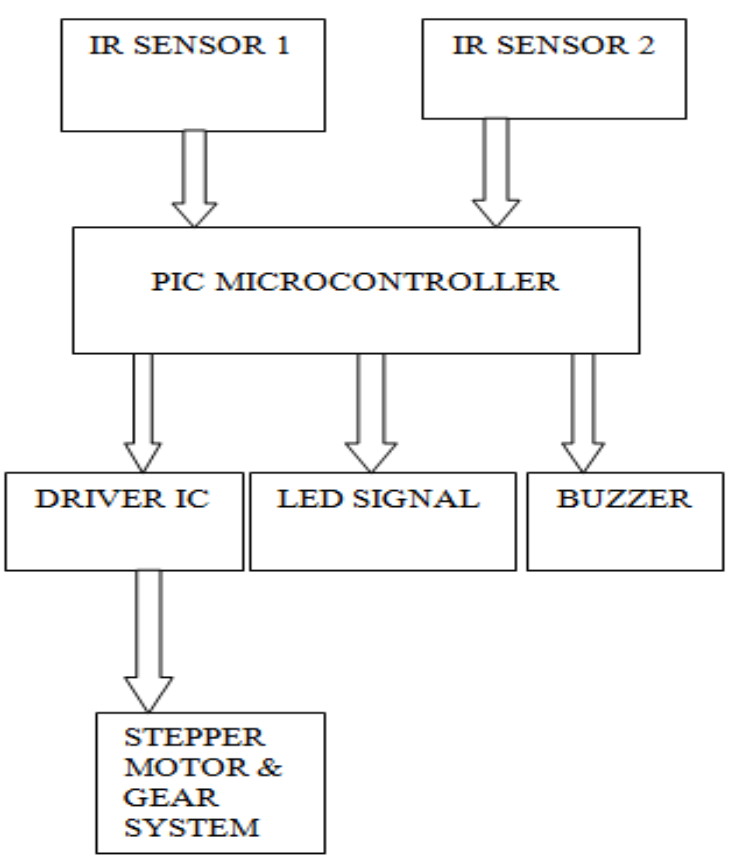

Fig 3: block diagram of gate controlling system 
The stepper motor has mainly three types of stepping, and those are single stepping, half wave stepping and full wave stepping. The stator of the stepper motor has four poles and the rotor has two poles. The input pulses are fed to the stator poles in a predefined sequence to obtain desired stepping angle and direction of rotation. The truth table for full step mode of operation for a four input stepper motor is given as follows,

Table.1 stepper motor truth table

\begin{tabular}{|l|l|l|l|l|}
\hline cycle & Coil 1 & Coil 2 & Coil 3 & Coil 4 \\
\hline A & 1 & 0 & 0 & 0 \\
\hline B & 0 & 1 & 0 & 0 \\
\hline C & 0 & 0 & 1 & 0 \\
\hline D & 0 & 0 & 0 & 1 \\
\hline
\end{tabular}

There are different types of electric motors are available. The conventional type induction motor, synchronous motors, dc motors are used widely and along with that some special electrical machines like stepper motors, brushless dc motors, servo motors, permanent magnet motors, switched reluctance motors etc. are also used according to the applications. Each of these motors has their unique characteristics and operational features and therefore the choice of suitable motor is very important for an electric drive. Many considerations has to be taken in selection of a motor for the electric drive.

The selection of the type of motor is based on the comparison as follows

Table. 2 selection of dc motor

\begin{tabular}{|l|l|l|}
\hline TYPE & ADVANTAGES & DISADVANTAGES \\
\hline $\begin{array}{l}\text { Stepper } \\
\text { Motor }\end{array}$ & $\begin{array}{l}\text { Very precise speed } \\
\text { and position } \\
\text { control. High } \\
\text { Torque at low } \\
\text { speed. }\end{array}$ & $\begin{array}{l}\text { Expensive and hard to } \\
\text { findr Require a } \\
\text { switching control } \\
\text { circuit }\end{array}$ \\
\hline $\begin{array}{l}\text { DC Motor } \\
\text { w/field coil }\end{array}$ & $\begin{array}{l}\text { Wide range of } \\
\text { speeds and torques. } \\
\text { More powerful } \\
\text { than permanent } \\
\text { magnet motors }\end{array}$ & $\begin{array}{l}\text { Require more current } \\
\text { than permanent magnet } \\
\text { motors, since field coil } \\
\text { must be energized. } \\
\text { Generally heavier than } \\
\text { permanent magnet } \\
\text { motors.. }\end{array}$ \\
\hline $\begin{array}{l}\text { DC } \\
\text { permanent } \\
\text { magnet } \\
\text { motor }\end{array}$ & $\begin{array}{l}\text { Small, compact, } \\
\text { and easy to find. } \\
\text { Very inexpensive }\end{array}$ & $\begin{array}{l}\text { Generally } \\
\text { Cannot vary magnetic } \\
\text { field strength. }\end{array}$ \\
\hline $\begin{array}{l}\text { Gasoline } \\
\text { (small two } \\
\text { stroke) }\end{array}$ & $\begin{array}{l}\text { Very hower/weight ratio. } \\
\text { provide Extremely } \\
\text { high torque. No } \\
\text { batteries required. }\end{array}$ & $\begin{array}{l}\text { Expensive, } \\
\text { difficult to mount, very } \\
\text { high vibration. }\end{array}$ \\
\end{tabular}

\section{CONCLUSION}

This project envisages the control of the platform system for a desired distance between the Gate and the IR sensors implemented successfully. The DC motor is controlled by the micro controller for a desired number of rotations by emulating the code of proper delay in to the micro controller.

This project, a scaled down model attempts to mimic the real time platform and its control. This can be realized in real time with the higher horse power motors, controlled by Programmable Logic Controllers and through several Distributed Control Systems (DCS).Every component used in this project must be realized in a larger scale so that it is possible to acquire the data from sensors, control the motor and hence the platform by PLC through proper linear gear mechanism and controlling the entire system automatically.

\section{ACKNOWLEDGMENTS}

I am grateful to god Almighty for His divine grace and blessings in making all this possible. I am indebted to the staff and management of my institution for providing all the necessary facilities to carry out this work. I express my sincere thanks to Asst. prof Mr. Subash Abraham Ponnuse, Head of the Department, for his support and guidance whose careful reviews improved the quality of this work. Also, I would like to thank all my teachers who supported me in making my venture fruitful. I would like to thank all my friends and my parents who supported me with encouragement for the completion of this work.

\section{REFERENCES}

[1] Microchip PIC kit programmer/debugger user's guide by microchip technology inc. 2008

[2] Bipolar stepper motor driver by MikroElektronica software and hardware solutions for embedded world

[3] An approach for automatic generation control by stepper motor using with PIC16F72 microcontroller, Sudip Das, Satadal Mal, Snehasish Pal, Debangshu Das, Assistant Professor, Department of Electrical Engineering, JIS College of Engineering

[4] Controlling DC Motor using Microcontroller (PIC16F72) with PWM Shruti Shrivastava, Jageshwar Rawat, Amit Agrawal Department of Electronics and Telecommunication Takshshila Institute of Engineering and Technology, Jabalpur, MP482001, India

[5] Microcontroller Based Clockwise/Anticlockwise Stepper Motor Controller using PC Keyboard Via Com Port Mandeep Singh, Rekha \& Balwinder Singh , Centre for Development of Advanced Computing (C-DAC), Mohali 160071, India

[6] Design of Wireless Home automation and security system using PIC Microcontroller V. Sathya Narayanan, S. Gayathri 1M.E EMBEDDED SYSTEM TECHNOLOGY, ANNA UNIVERSITY, Coimbatore, India.

[7] Efficient Solutions for Industrial Motor Control and Drives by Infineon journal. 
[8] The 8051 microcontroller and embedded systems, Muhammad Ali Mazidi, Janice Gillespie Mazidi, Pearson Education(2005)

[9] Dc motor driver IC , SLVSAB9D -MAY 2010 REVISED AUGUST 2013 by Texas Instruments.

[10] www.microchip.com

[11] www.electrohub.com

[12] www.cytron.com

[13] www.electronica.com 